\title{
Intratumoral electroporation of plasmid interleukin-12: efficacy and biomarker analyses from a phase 2 study in melanoma (OMS-1100)
}

\author{
Adil Daud ${ }^{1}$, Alain Algazi ${ }^{1}$, Michelle Ashworth', Michael Buljan', Kathryn Toshimi Takamura², Tu Diep²*, \\ Robert $\mathrm{H}$ Pierce $^{2}$, Shailender Bhatia ${ }^{3}$ \\ From Melanoma Bridge Meeting 2014 \\ Naples, Italy. 03-06 December 2014
}

\section{Background}

Recent data from immune checkpoint studies, including studies of anti-PD1 and anti-PDL1 antibodies, suggest that an inflammatory intratumoral milieu is required for an optimal response to immune therapy. Serial biopsy analyses from a phase 1 study demonstrate that transformation of tumor cells with electroporation (EP) of plasmid interleukin-12 (pIL-12) promotes this inflammatory immune milieu. Here we present clinical response data for 30 advanced melanoma patients (pts) treated with PIL-12 EP in a phase 2 trial (OMS-I100). We also present additional safety and more detailed biomarker data demonstrating the promotion of pro-inflammatory genes with PIL-12 EP therapy.

\section{Methods}

Thirty patients with stage IIIB-IV melanoma received up to 4 cycles of pIL-12 EP into superficial cutaneous, subcutaneous, and nodal lesions on days 1, 5 and 8 of each 12 -week cycle. Tumor responses were evaluated using modified RECIST criteria for cutaneous lesions. Adverse events (AEs) were assessed using CTCAE version 4. Alterations in transcription were assessed by comparing pre- and post-treatment biopsies from treated lesions using NanostringTM technology to identify pharmacodynamic markers of downstream pathway activation and to characterize cellular infiltration.

\section{Results}

The best overall response rate (BORR) by modified RECIST in 29 evaluable pts was 31\% (9/29), with $10 \%$
(3/29) of pts achieving a CR. Regression of at least one non-treated lesion was seen in 54\% (13/24) of pts with evaluable lesions. The most common treatment-related adverse event (AE) reported was transient Grade 1/2 pain at the treatment site, reported in $87 \%(26 / 30)$ of pts. Grade 3 adverse events were rare and included only 1 report of Grade 3 pain at the injection site. No grade 4 or higher adverse events were observed. Analysis of tissue samples from patients treated with pIL-12 EP showed a gene expression pattern consistent with downstream activation of NK cells and interferon- $\gamma$-dependent genes, including key genes responsible for tumor inflammation, antigen processing and presentation (APM).

\section{Conclusions}

pIL-12 EP monotherapy induces objective tumor responses in a significant proportion of patients (BORR 31\%) and treatment was well tolerated. pIL-12 EP promotes the expression of pro-inflammatory genes including genes required for antigen processing and presentation. Regression of non-treated lesions suggests successful induction of systemic anti-tumor immune-mediated effects. Based on these data, further investigation of pIL-12 EP both as a single agent, and in combination with other therapies such as anti-PD1/ PD-L1, is warranted.

\section{Authors' details}

'University of California, San Francisco - San Francisco, California, USA. ${ }^{2}$ OncoSec Medical Inc. - San Diego, California, USA. ${ }^{3}$ University of Washington - Seattle, Washington, USA.

${ }^{2}$ OncoSec Medical Inc. - San Diego, California, USA

Full list of author information is available at the end of the article 
doi:10.1186/1479-5876-13-S1-011

Cite this article as: Daud et al: Intratumoral electroporation of plasmid interleukin-12: efficacy and biomarker analyses from a phase 2 study in melanoma (OMS-I100). Journal of Translational Medicine 2015 13(Suppl 1): 011.

Submit your next manuscript to BioMed Central and take full advantage of:

- Convenient online submission

- Thorough peer review

- No space constraints or color figure charges

- Immediate publication on acceptance

- Inclusion in PubMed, CAS, Scopus and Google Scholar

- Research which is freely available for redistribution 